\title{
Response of urban heat island to future urban expansion over the Beijing-Tianjin-Hebei metropolitan area
}

\author{
Juan Wang a, b, Bo Huang b, c, d, *, Dongjie Fu ${ }^{\mathrm{e}}$, Peter M. Atkinson ${ }^{\text {f, g, h, i }}$, Xuezhen Zhang ${ }^{\mathrm{j}}$ \\ ${ }^{a}$ College of Applied Arts and Science, Beijing Union University, Haidian District, Beijing 100191, China \\ ${ }^{\mathrm{b}}$ Department of Geography and Resource Management, The Chinese University of Hong Kong, Shatin, NT, Hong Kong, China \\ ' Shenzhen Research Institute, The Chinese University of Hong Kong, No. 10, 2nd Yuexing Road, Nanshan District, Shenzhen 518057, China \\ ${ }^{\mathrm{d}}$ Institute of Space and Earth Information Science, The Chinese University of Hong Kong, Shatin, NT, Hong Kong, China \\ e State Key Laboratory of Remote Sensing Science, Institute of Remote Sensing and Digital Earth, Chinese Academy of Sciences, Beijing 100101, China \\ ${ }^{\mathrm{f}}$ Faculty of Science and Technology, Engineering Building, Lancaster University, Lancaster LA1 4YR, UK \\ ${ }^{\mathrm{g}}$ Faculty of Geosciences, University of Utrecht, Heidelberglaan 2, 3584 CS Utrecht, The Netherlands \\ ${ }^{\mathrm{h}}$ School of Geography, Archaeology and Palaeoecology, Queen's University Belfast, Belfast BT7 1NN, Northern Ireland, UK \\ ${ }^{\mathrm{i}}$ Geography and Environment, University of Southampton, Highfield, Southampton SO17 1BJ, UK \\ ${ }^{\mathrm{j}}$ Key Laboratory of Land Surface Pattern and Simulation, Institute of Geographical Sciences and Natural Resources Research, Chinese Academy of Sciences, \\ Beijing 100101, China
}

\section{A R T I C L E I N F O}

\section{Article history:}

Received 28 August 2014

Received in revised form

19 December 2015

Accepted 1 February 2016

Available online 22 March 2016

\section{Keywords:}

Urban heat island

Urban expansion

Land use/land cover

Beijing-Tianjin-Hebei metropolitan area

Weather research and forecast model

\begin{abstract}
A B S T R A C T
Urban expansion plays a dominant role in the urban heat island (UHI) formation and is thus the essence and fundamental characteristic of the urban fabric. In this study, the responses of UHI to the urban expansion in the past decades were simulated using the coupled weather research forecast/urban canopy model (WRF/UCM) system from the 1980s to 2005 and in the future in 2050 embedded with the fine spatial resolution land use/land cover (LULC) datasets over the Beijing-Tianjin-Hebei (BTH) metropolitan area. With the urban expansion, the validations suggested that the designed models in this research can well simulate the generation and development of UHI. Due to urban expansion, the minimum temperature would rise by about $5 \mathrm{~K}$ in the newly developed areas. The temperature over the old urban areas would also increase $(<1 \mathrm{~K})$ because of the surrounding newly developed urban areas. The footprint of urban growth, in particular the minimum temperature, was clearly captured in the three scenarios by almost all the variables. These results were quite interesting, and it indicated a more uncomfortable urban environment in the future, especially at night, when the temperature changes are larger due to urban expansion.
\end{abstract}

() 2016 Elsevier Ltd. All rights reserved.

\section{Introduction}

There has been a surge of urban expansion in China, with urban areas increasing by over 20\% from 1980 to 2005 (Liu \& Tian, 2010). In view of high economic growth and population density in China, there is an upward trend seen in urbanization. Urban climate phenomenon (UHI) has been the result of the urbanization process accompanied by the conversion from rural to urban. Statistical models, in particular correlation and regression, have been employed widely to determine the effect of urbanization on surface UHI (SUHI). Land surface temperature (LST) derived from thermal infrared (TIR) remote sensing images correlated with

\footnotetext{
* Corresponding author. Department of Geography and Resource Management, The Chinese University of Hong Kong, Shatin, NT, Hong Kong, China.

E-mail address: bohuang@cuhk.edu.hk (B. Huang).
}

LULC change, built-up areas, and vegetation in cities (Bounoua, Safia, Masek, Peters-Lidard, \& Imhoff, 2009; Chen, Zhao, Li, \& Yin, 2006; Connors, Galletti, \& Chow, 2013; Guo, Wang, Cheng, \& Shu, 2012; He, Liu, Zhuang, Zhang, \& Liu, 2007; Weng, Lu, \& Schubring, 2004, 2006; Zhang et al., 2013). Although statistical models are useful to describe the patterns and explore the associated factors of the UHI, they cannot reveal the generation and development of UHI (Voogt \& Oke, 2003). In addition, remote sensing images measure only the surface skin temperature, while the near-surface air temperature correlates more to human comfort. Although these two types of temperatures are closely related, they are actually different (Gallo, Hale, Tarpley, \& Yu, 2011). A series of sensitivity experiments are necessary to get a deeper insight into the UHI and the effects of urban expansion on UHI from a modeling perspective.

Recently, the weather research forecast (WRF) numerical 
modeling system (Skamarock et al., 2005) has attracted much attention. This meso-scale numerical modeling system is designed for atmospheric research and operational forecasting. Some large cities and urban agglomerations, such as Tokyo (Kusaka \& Kimura, 2004), Taipei (Lin et al., 2008; Lin, Chen, Chang, \& Sheng, 2010), Nanjing (Yang, Zhang, \& Qian, 2012), and Beijing (Miao et al., 2009; Zhang et al., 2009), as well as Yangtze River Delta (Zhang, Gao, Wang, \& Chen, 2010), the BTH metropolitan area (Wang, Yan, Liu, \& Zhang, 2013, Wang, Zhang, \& Yan, 2013), and Pearl River Delta (Cheng \& Chan, 2012; Wang, Wu, \& Liang, 2009), have witnessed the simulation of the variation in UHI using this modeling system. The capability of the WRF modeling system has been highlighted to explore the impact of LULC change on UHI at the local or regional scales. However, when simulating the effect of urban expansion on UHI (Wang, Feng, Yan, Hu, \& Jia, 2012), most studies focused only on the ideal experiments (e.g., replacing urban areas by cropland), which is insufficient to characterize the real urbanization process. The default LULC data from the United States Geological Survey (USGS) or Moderate Resolution Imaging Spectroradiometer (MODIS) products in the WRF modeling system may lead to bias because of its coarse spatial resolution (Lin et al., 2010). To simulate the effect of urban expansion on the UHI over the BTH metropolitan area, in this study, the coupled WRF/UCM modeling system embedded with three periods of fine spatial resolution LULC data were used. Part of this study included scenarios of future urbanization simulated using LULC predicted by a land conversion model (Huang, Zhang, \& Wu, 2009).

\section{Study area and data}

\subsection{Study area}

The BTH metropolitan area is situated in the North China Plain. Since being branded as an economic center of northern China, this area has undergone dramatic economic growth and massive urbanization from the time of the reform process in late 1978. The total residential population over this region has doubled from 1984 to 2008 (China City Statistical Yearbook, 2009). Likewise, the builtup area expanded to a large extent taking up areas which were previously agricultural zones. This study takes the metropolis area as the study area, including Beijing, Tianjin, and most parts of Hebei province, which is indicated by the inner rectangle in Fig. 1. The two red rectangles represent the two domains in WRF model design, which is explained in Section 3.

\subsection{Data}

\subsubsection{Land use and land cover dato}

LULC datasets in the 1980s and 2005 covering the BTH metropolis area were obtained from "Data Sharing Infrastructure of Earth System Science, the Chinese Academy of Sciences (DSIESS,CAS)" (http://www.geodata.cn/Portal/metadata/viewMetadata.jsp? $\mathrm{id}=100101-11860)$. They have a high accuracy of $80-90 \%$ when compared to extensive field surveys (DSIESS, CAS). These datasets have a fine spatial resolution ( $100 \mathrm{~m}$ by $100 \mathrm{~m}$ ) and are suitable for characterizing urban growth between the 1980s and 2005.

To embed the fine spatial resolution LULC data into the WRF modeling system, they were resampled to dimensions of $1 \times 1 \mathrm{~km}$ using the "majority" resampling technique. They were then reclassified according to the default USGS-24 categories and reprojected to WGS-84. The final LULC maps are shown in Fig. 2a, b. The LULC in 2050 (Fig. 2c) was predicted using the statistical land conversion model by Huang et al. (2009), which is introduced in Section 3.1. The three periods of LULC data in the 1980s, 2005, and 2050 were used to characterize the real urbanization process in the past decades and the future possible pattern of urbanization. All of them were finally embedded into the coupled WRF/UCM modeling system.

\subsubsection{Reanalysis data}

Reanalysis data used in this research were obtained from the "National Centers for Environmental Prediction/Global Forecast System (NCEP/GFS)" (http://www.nco.ncep.noaa.gov/pmb/products/ $\mathrm{gfs} /$ ). The datasets provide both the initial and the boundary conditions on $1^{\circ}$ by $1^{\circ}$ grids at every $6 \mathrm{~h}$ continuously (including 00:00, 06:00, 12:00, 18:00) for the WRF simulation.

\subsubsection{Meteorological data}

To validate the accuracy of the designed model in this study, the air temperature data were obtained from the "China Meteorological Data Sharing System” (http://cdc.cma.gov.cn/home.do). Nineteen meteorological stations distributed in the study areas were used, which are listed in Section 3.

\section{Methodology}

\subsection{Statistical land conversion model}

In this study, a statistical land conversion model developed by Huang et al. (2009) was used to simulate urban-rural LULC conversion. This model was proposed by establishing the logistical regression relationship between the land change (e.g., zero was considered as "no change", 1 was considered as "change") and the explanatory factors. In this study, the urban-rural conversion in the year 2050 was forecasted. To produce the dependent urban-rural map in the 1980s and 2005, the urban built-up areas were reclassified as the "urban" category, the seas and deserts were reclassified as "others", and all the other types were reclassified as the "rural" category. Five explanatory factors, including percentage of urban area, Euclidian distance to urban area, Euclidian distance to roads, population density, and slope, were employed to predict land conversion from rural to urban areas. The datasets, which were used to derive the explanatory factors, were obtained from the DSIESS, CAS, including road, population density, and digital elevation data.

\subsection{WRF/UCM simulation}

\subsubsection{Parameterization schemes}

The UCM, together with the newest 3.5.1 version of the WRF modeling system, was employed in this study. With the spatial resolution adjusted at $20 \mathrm{~km}$ for the outer domain and $4 \mathrm{~km}$ for the inner domain, respectively, two levels in a nested grid were used (Fig. 1). The inner nested urban domain, D02, was centered over the BTH metropolitan area. The outer domain, D01, covering most of northern China, presented the boundary conditions for the inner domain. The geophysical coordinate system adopted in this study was the Lambert projection.

In the case of the input parameters required by the WRF modeling system, the initial boundary conditions were supplied by the NCEP/GFS 6-hourly reanalysis data (see Section 2.2.2, Reanalysis data). The terrestrial, geographical input data had a spatial resolution of 30". The default USGS LULC data were replaced by the fine spatial resolution LULC data (see Section 2.2.1, Land use and land cover data). The main physical parameterization schemes adopted in this study are shown in Table 1.

The simple single-layer UCM was used to take the geometry of urban areas into account in the wind shear and surface energy budget calculations (Chen et al., 2004, 2011; Kusaka, Kondo, Kikegawa, \& Kimura, 2001). As it is difficult to obtain the detailed 


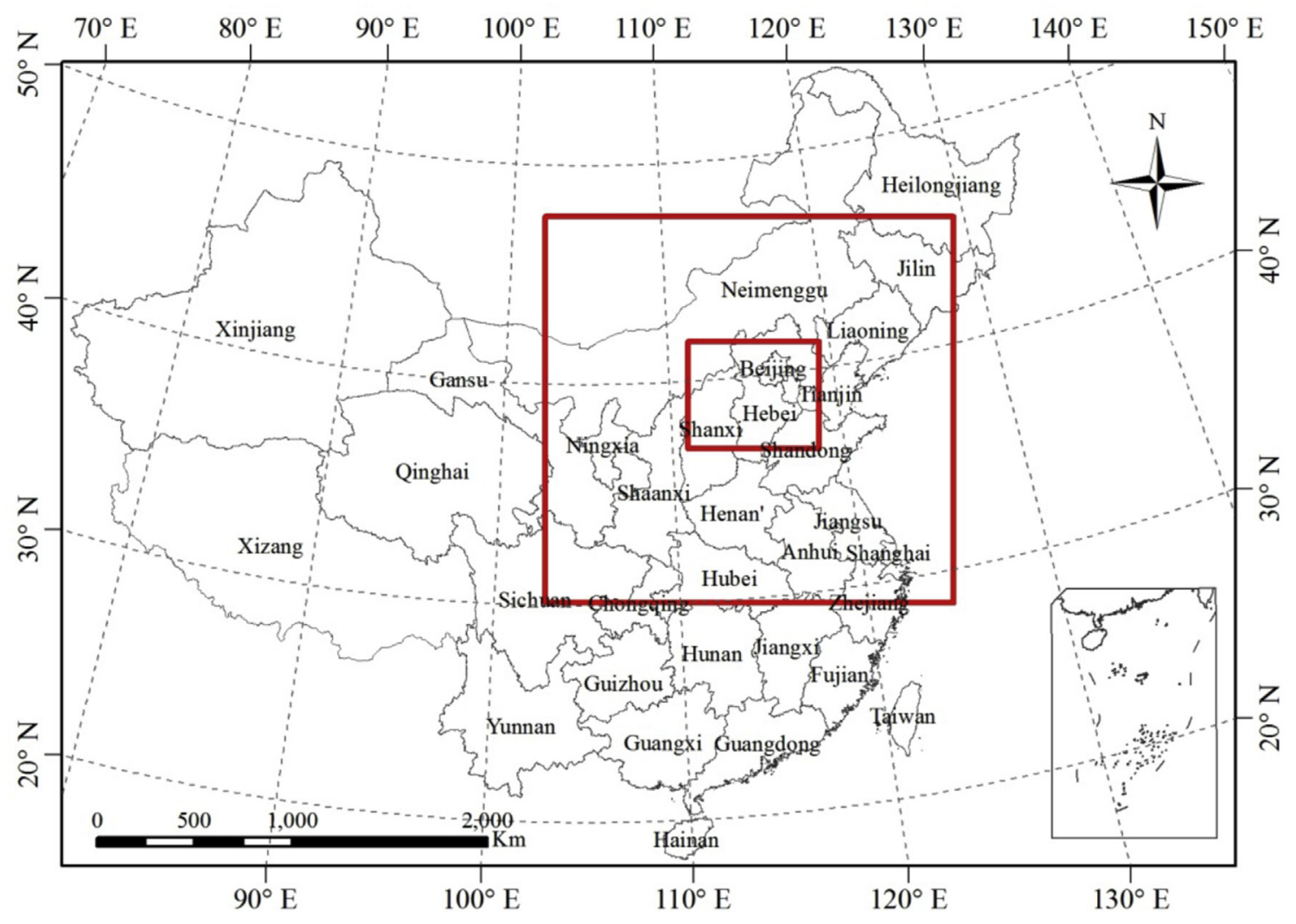

Fig. 1. Study area and the two nested domains in WRF simulations.

urban structures for all cities over the study area, the uniform urban canopy parameters and the default hourly diurnal profile of anthropogenic heat in a typical urban area set in the UCM were employed in this study (Table 2).

\subsubsection{Experiments design}

During the study period and the two-level nested spatial domains (Chen et al., 2011; Skamarock et al., 2005), the global and regional warming effects were embedded in all the simulation scenarios by the input reanalysis data. This study also included sensitivity experiments by changing the underlying LULC data to explore the impacts of urban expansion on the UHI. In addition, the BTH metropolitan region has a subhumid warm temperate continental monsoon climate with a cold and windy winter, a hot and humid summer, and transitional periods in spring and autumn (Qiao, Tian, \& Xiao, 2013). Likewise, the distinct seasonal variations in the UHI have also been described, with the UHI reaching its peak intensity in summer, much lesser in spring and autumn, and negative in winter (Liu, Li, \& Zhu, 2014; Wang, Wang, \& Wang, 2007; Yang, Zhao, Shen, Hai, \& Fang, 2010). As we intended to explore the effect of urbanization on the UHI, given the huge computer resources and time-cost when running the WRF experiments, we picked the winter and summer periods for the study. In all, three scenarios were designed in this study, including the 1980s, 2005, and 2050. Simulated experiments were conducted during January and July to present the winter and summer periods, respectively, comparing the seasonal variations in UHI. Specifically, six experiments were carried out. Each case was started at local time 00:00, with the first 2 days being allocated for model spin-up to minimize the effect of initial conditions. To represent current urban conditions, the LULC data in 2005 were used, and the two cases in 2005 were used as control experiments to validate the performance of the designed models. The experiments in the 1980s and 2050 were used as the compared experiments presenting the early and future urbanization simulations, respectively.

\section{Results and discussion}

\subsection{Validation of the control experiments}

The performance of the two control experiments in January and July in 2005 was tested by comparing the simulated 2-m temperature and $10-\mathrm{m}$ wind speed with the observed air temperature and wind speed from 19 meteorological stations in the study area (Fig. 3). A simulated average of $2-\mathrm{m}$ temperature and $10-\mathrm{m}$ wind speed was achieved within the $3 \times 3$ pixels surrounding each meteorological station. In January, the correlation coefficient (CC) between the observed and simulated values was significant at the 0.001 level (CC: 0.84 for the temperature and 0.86 for the wind speed). Although a slightly larger absolute error existed for some dates, such as July 14 , the overall trend of simulated 2-m temperature was consistent with the observed air temperatures from the meteorological stations in July. The CC between the observed and simulated values (CC: 0.37 ) was significant at the 0.05 level. The simulated wind speed in July was not well matched with the observed values (CC: 0.1 ), the reasons for which will be explained later.

The monthly averaged simulated 2-m temperature was also compared with the monthly average observed air temperature for each station (Table 3). In January, most of the root mean square errors (RMSE) were below $1^{\circ} \mathrm{C}$. The absolute errors for most of the stations were within $2{ }^{\circ} \mathrm{C}$ except in Weixian, Bohai $\mathrm{A}$, Chengde, and Zhangjiakou. In July, the RMSE was around $1.5^{\circ} \mathrm{C}$ for most of the stations, while both the absolute errors varied between the 

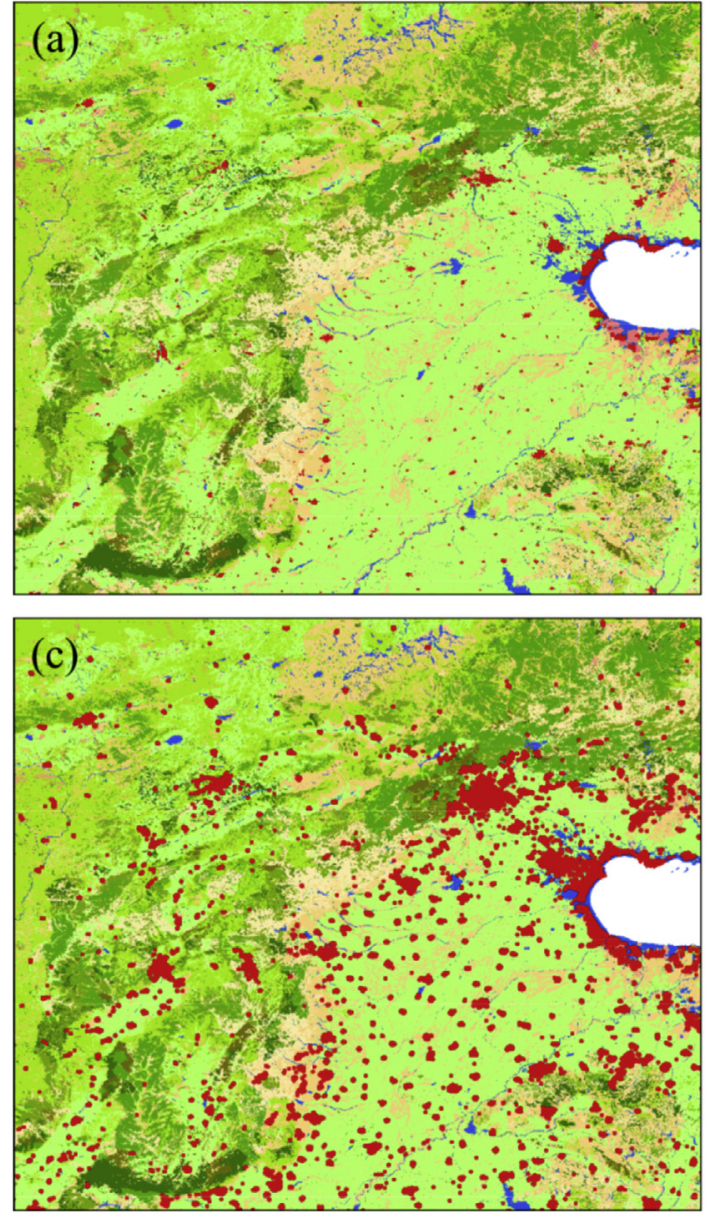

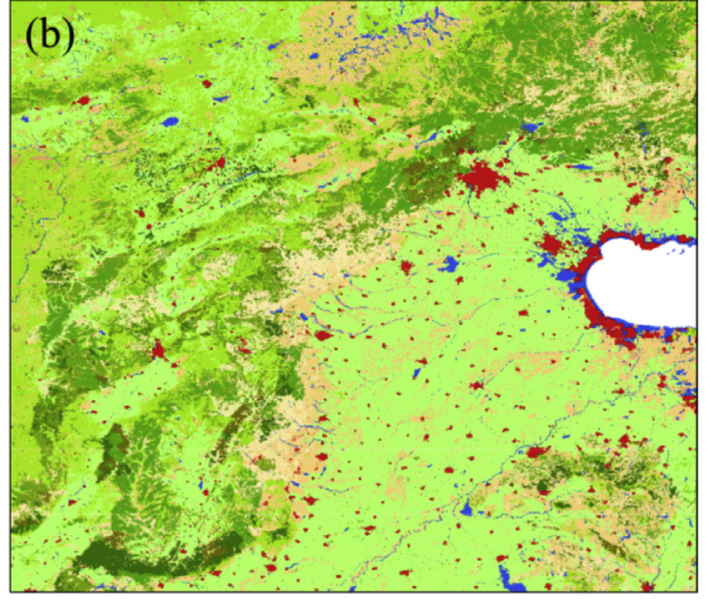

Urban and Built-up Land

Dryland Cropland and Pasture

Irrigated Cropland and Pasture

$\square$ Cropland/Grassland Mosaic

$\checkmark$ Cropland/Woodland Mosaic

Grassland

Shrubland

Savanna

Deciduous Broadleaf Forest

Deciduous Needleleaf Forest

Evergreen Broadleaf

Evergreen Needleleaf

Mixed Forest

Water Bodies

Herbaceous Wetland

Barren or Sparsely Vegetated

Wooded Tundra

Mixed Tundra

Fig. 2. Land use/land cover types in (a) the 1980s, (b) 2005, (c) 2050 in the study area.

Table 1

Physical parameterization schemes used in this study.

\begin{tabular}{ll}
\hline Physical processes & Parameterization scheme \\
\hline Microphysics scheme & WSM 3-class simple ice scheme \\
Cumulus scheme & Grell-Devenyi ensemble scheme \\
Surface layer & Monin-Obukhov scheme \\
Land surface process & Noah land surface model \\
Planetary boundary layer process & YSU scheme \\
Long-wave radiation & RRTM scheme \\
Short-wave radiation & Dudhia scheme \\
\hline
\end{tabular}

The bias Cheng \& Chan, 2012between the observed and simulated values may be caused by the following factors. First, the spatial extent of the observed values used for the validation was not perfectly consistent with that of the simulated values, which were averaged within the $3 \times 3$ pixels surrounding the metrological station, with the pixel size equal to $4 \times 4 \mathrm{~km}$. By contrast, the observed values were obtained from just one point at the metrological station. There may be a bias caused by the spatial heterogeneity. Second, the default parameters in the UCM were adopted in this study, such as the height of the building height, width of the

Table 2

Default parameters in the coupled WRF/UCM modeling system.

\begin{tabular}{|c|c|c|}
\hline Description & Value & Units \\
\hline Building height & 7.5 & $\mathrm{~m}$ \\
\hline Road width & 9.4 & $\mathrm{~m}$ \\
\hline $\begin{array}{l}\text { Fraction of the urban landscape occupied by artificial } \\
\text { materials }\end{array}$ & 0.9 & \\
\hline Surface emissivity of roof/building all/road & 0.9 & \\
\hline Surface albedo of roof/building all/road & 0.2 & \\
\hline Anthropogenic heat & 50 & $\mathrm{Wm}^{-2}$ \\
\hline $\begin{array}{l}\text { Hourly diurnal profile for anthropogenic heat (starting at } \\
01 \mathrm{~h} \text { local time) }\end{array}$ & $\begin{array}{l}0.16,0.13,0.08,0.07,0.08,0.26,0.67,0.99,0.890 .79,0.74,0.73,0.75,0.76,0.82,0.90,1.00,0.95,0.68 \text {, } \\
0.61,0.53,0.35,0.21,0.18\end{array}$ & \\
\hline
\end{tabular}

Sources: Wang et al. (2012).

stations, with the largest vales $\left(3.59{ }^{\circ} \mathrm{C}\right)$ in Beijing station and the smallest value $\left(-0.13^{\circ} \mathrm{C}\right)$ in Bohai A station. street, and anthropogenic heat discharge. In practice, these are likely to be different from the actual conditions in the study area, 

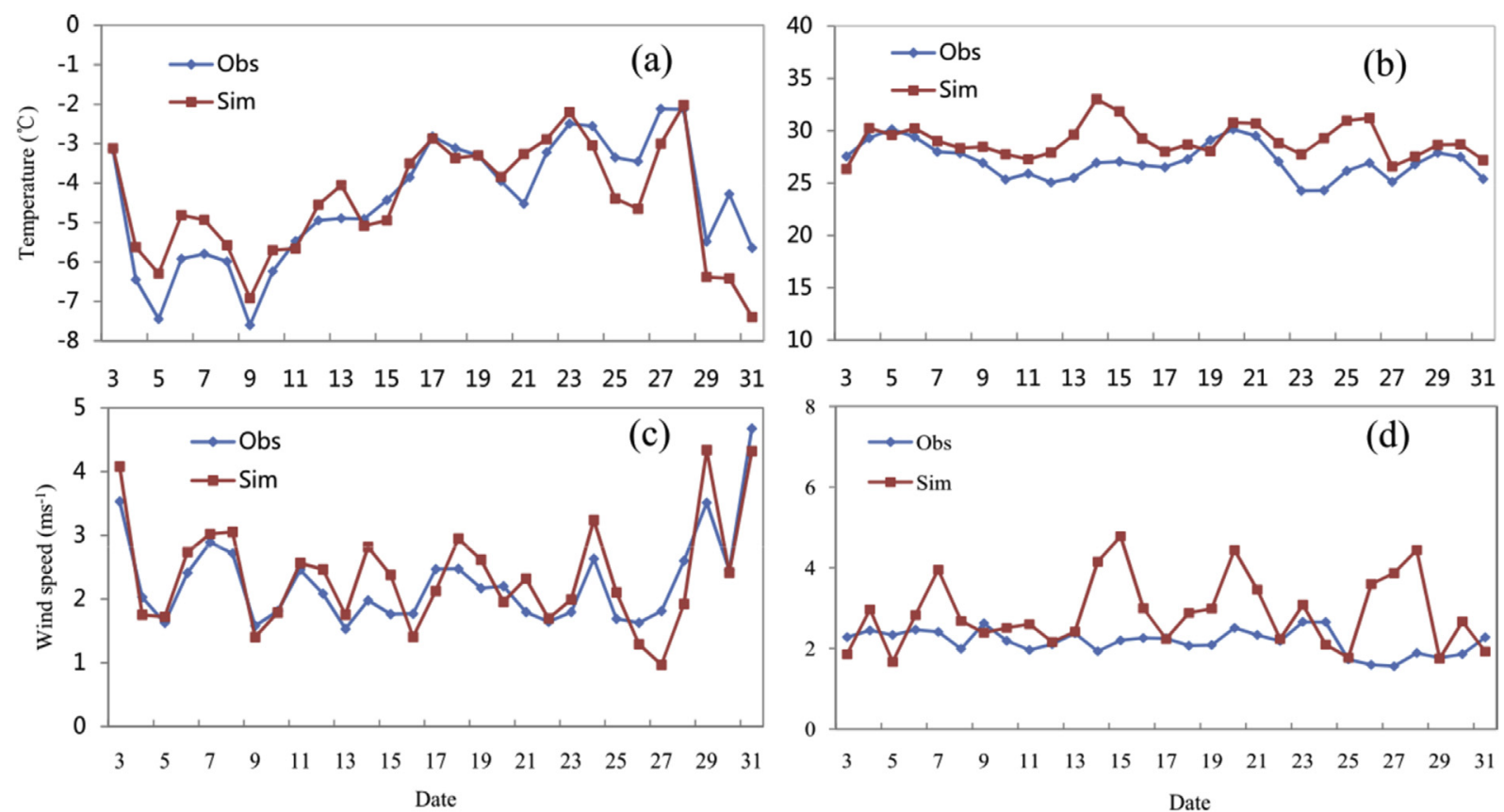

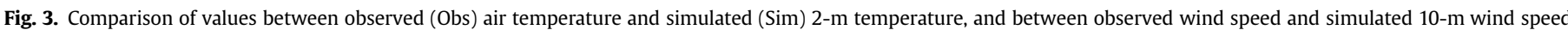
averaged spatially across 19 meteorological stations. Left: January; Right: July.

Table 3

Comparison between observed air temperature and simulated 2-m temperature for each meteorological station (units: ${ }^{\circ} \mathrm{C}$ ).

\begin{tabular}{|c|c|c|c|c|c|c|c|c|c|}
\hline \multirow[t]{2}{*}{ Station ID } & \multirow[t]{2}{*}{ Station name } & \multicolumn{4}{|l|}{ January } & \multicolumn{4}{|l|}{ July } \\
\hline & & Obs & Sim & RMSE & $\mathrm{AE}$ & Obs & Sim & RMSE & $\mathrm{AE}$ \\
\hline 54511 & Beijing & -2.58 & -3.45 & 0.78 & -0.87 & 27.72 & 31.31 & 1.59 & 3.59 \\
\hline 54416 & Miyun & -5.77 & -4.42 & 0.98 & 1.35 & 26.50 & 28.84 & 1.28 & 2.33 \\
\hline 54705 & Nangong & -3.25 & -3.06 & 0.36 & 0.19 & 27.73 & 31.10 & 1.54 & 3.36 \\
\hline 54624 & Huanghua & -2.68 & -3.92 & 0.93 & -1.24 & 28.21 & 30.40 & 1.24 & 2.19 \\
\hline 54618 & Botou & -3.41 & -3.89 & 0.59 & -0.48 & 28.21 & 31.25 & 1.47 & 3.04 \\
\hline 54606 & Raoyang & -4.50 & -4.28 & 0.39 & 0.21 & 27.62 & 30.98 & 1.54 & 3.36 \\
\hline 54602 & Baoding & -2.81 & -4.08 & 0.95 & -1.27 & 28.47 & 31.84 & 1.54 & 3.36 \\
\hline 54534 & Tangshan & -3.40 & -4.41 & 0.85 & -1.01 & 27.27 & 28.44 & 0.91 & 1.17 \\
\hline 54518 & Langfang & -3.48 & -4.91 & 1.01 & -1.43 & 27.77 & 30.83 & 1.47 & 3.06 \\
\hline 54429 & Zunhua & -4.84 & -4.71 & 0.31 & 0.13 & 26.54 & 27.88 & 0.97 & 1.34 \\
\hline 54423 & Chengde & -9.80 & -7.69 & 1.22 & 2.11 & 23.91 & 24.54 & 0.67 & 0.63 \\
\hline 54405 & Huailai & -6.89 & -7.18 & 0.45 & -0.29 & 26.00 & 27.06 & 0.87 & 1.06 \\
\hline 54401 & Zhangjiakou & -8.38 & -11.02 & 1.37 & -2.64 & 24.90 & 25.27 & 0.51 & 0.37 \\
\hline 53798 & Xingtai & -1.19 & -1.49 & 0.46 & -0.30 & 28.65 & 30.84 & 1.24 & 2.19 \\
\hline 53698 & Shijiazhuang & -2.08 & -1.79 & 0.45 & 0.29 & 28.64 & 30.99 & 1.29 & 2.34 \\
\hline 53593 & Weixian & -12.49 & -10.10 & 1.30 & 2.38 & 24.34 & 23.91 & 0.55 & -0.43 \\
\hline 54646 & Bohai A & -1.11 & 1.85 & 1.45 & 2.96 & 26.50 & 26.37 & 0.31 & -0.13 \\
\hline 54623 & Tanggu & -2.46 & -2.48 & 0.11 & -0.02 & 28.15 & 29.46 & 0.96 & 1.30 \\
\hline 54527 & Tianjin & -3.77 & -4.01 & 0.42 & -0.25 & 27.73 & 30.44 & 1.38 & 2.71 \\
\hline
\end{tabular}

Obs: Observed values; Sim: simulated values; AE: Absolute error.

which may introduce errors to the simulated values in urban areas. Third, the validation of the model performance revealed lower accuracy in summer than in winter, which was also reported by previous studies (Cheng \& Chan, 2012). This may be caused by the frequent rainfall experienced in summer in the study area $(\mathrm{Wu}, \mathrm{Hu}$, \& Kirtman, 2003). Overall, as we focused on the effects of different LULC in this research, this bias can be considered as a systematic model error that will not affect the applicability of the conclusions.

\subsection{Diurnal and seasonal variation in UHI at the fine spatial resolution}

As there were differences in heat fluxes between rainy days and dry days (Yang et al., 2012), experiments on dry days were the ones picked and analyzed in this study. If the stations (e.g., Beijing, Miyun, Tianjin, Tanggu, Shijiazhuang, Tangshan) typically received no precipitation, the days were considered dry. In July, the 5th, 6th, 25th, 26th, and the 29th were the dry days, while in January, except 5 th and 6th, all the days were dry. The simulated surface skin temperatures at local times 02:00, 08:00, 14:00, and 20:00 in January and July 2005 are presented in Fig. 4. The SUHI was observed to be distinct in July, while the SUHI in January was not so obvious. In the case of the SUHI in July, the nighttime SUHI at 02:00 and 20:00 was much larger than the daytime SUHI at 08:00 and 14:00. The spatial pattern of $2-m$ temperature was consistent with the surface skin temperature (figures are not shown here). The air UHI (AUHI) in July was significantly larger than that in January, while the nighttime AUHI in July was significantly greater than the 

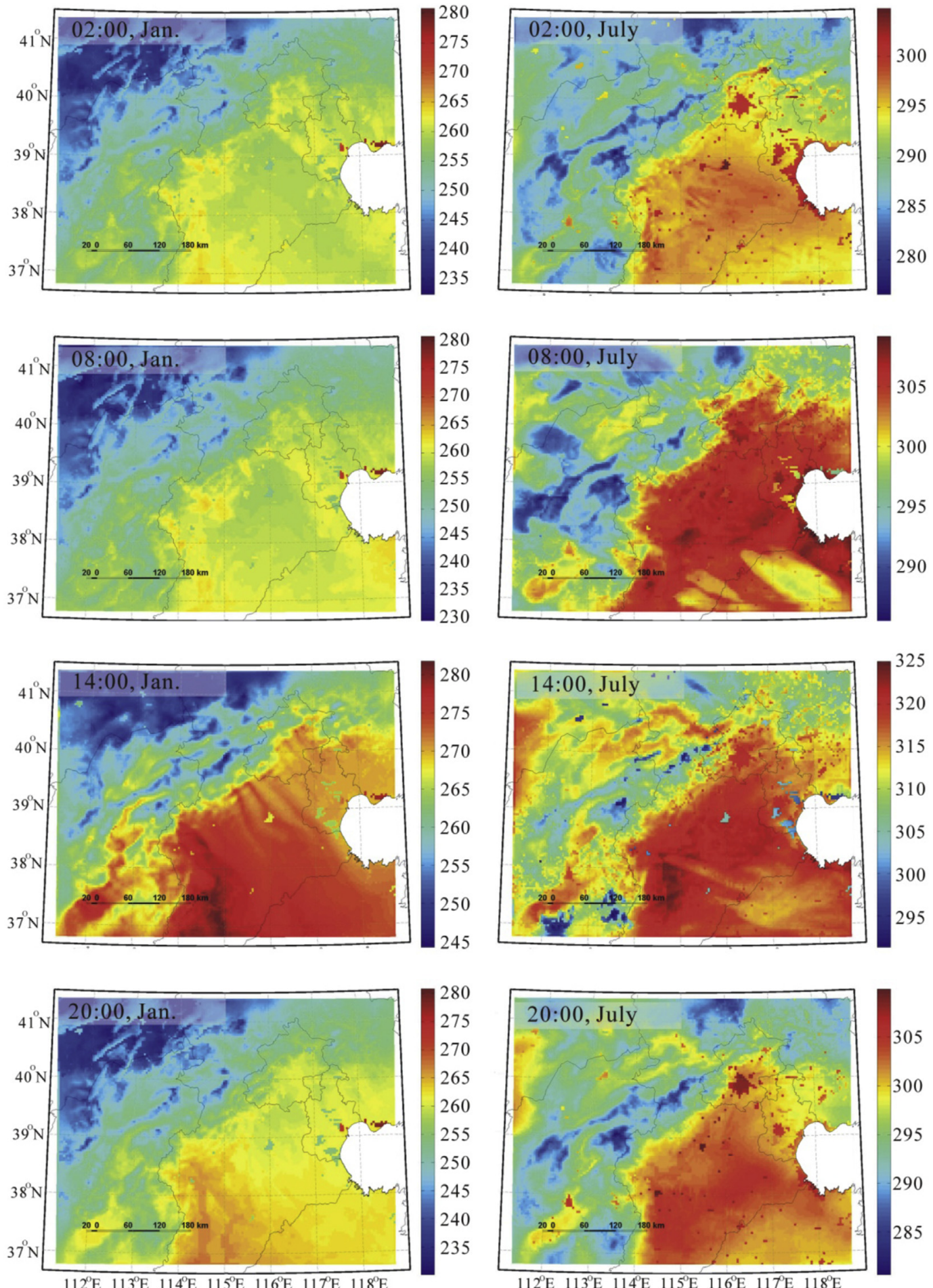

Fig. 4. Surface skin temperature (TSK) at 02:00, 08:00, 14:00, and 20:00 (from top to bottom). Left: January; Right: July.

daytime AUHI.

The SUHI intensity (SUHI) and AUHI intensity (AUHII) were calculated by subtracting the average temperature in urban areas (here urban and built-up land) from the average temperature in rural areas (here cropland). Fig. 5 shows the diurnal variation of both the SUHII and AUHII in July 2005. The AUHII was lower than the SUHII for the entire day. The SUHII was larger during the night and reached the highest value $(6 \mathrm{~K})$ around $04: 00$. It was much smaller during the daytime and had the smallest value $(2 \mathrm{~K})$ around
12:00. Generally, the trend of the diurnal variation of AUHII was consistent with the SUHII, but with about $2 \mathrm{~K}$ lower temperature than the SUHII during the nighttime and about $1 \mathrm{~K}$ lower during the daytime. Overall, both the simulated 2-m AUHII and SUHII were larger during the nighttime than during the daytime.

In other studies (Liu et al., 2014; Wang et al., 2007; Yang et al., 2010), the greatest UHI intensity in summer and the very small UHI (even the "cool" island) in winter were also observed. This can be explained by differences in vegetation coverage and the human 


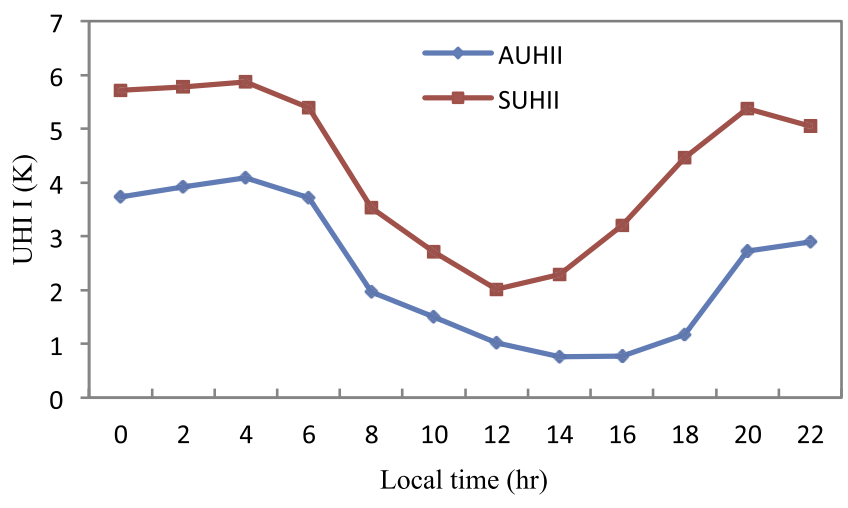

Fig. 5. Diurnal variation in simulated $2-\mathrm{m}$ air UHII (AUHII) and surface UHII (SUHII) in July 2005.

heat discharge between urban and rural areas during summer and winter. During summer, significant negative correlations between the vegetation and the surface temperatures were documented, which suggests that the greater the vegetation coverage, the lower the temperature (Gallo and Tarpley, 1996; Weng, 2009). This essentially is a result of the absorption and transpiration effect of vegetation. During summer, the vegetation coverage in the urban areas was much lower in comparison to rural areas in the BTH metropolitan area (Zhang, Hou, Li, Yan, \& Yang, 2005). Then, in summer, the rural areas with greater vegetation coverage would have lower temperatures than urban areas. Besides, the large human heat released by air conditioning in buildings, industrial production, and combustion engines, etc., in the urban areas can also increase temperatures in the urban areas in comparison to rural areas. In winter, the vegetation coverage in both the rural and urban areas in the BTH metropolitan region is low. Large areas of bare soil exist in the rural areas, which can store a large amount of heat with higher temperatures. In contrast, cold sources in such cold building surfaces in urban areas may make urban areas cool in winter. Besides, the BTH metropolitan area is located in the northern hemisphere. The low solar altitude creates shadows from buildings in urban areas in winter, which also lead to less shortwave radiation in the shadows and lower temperatures in urban areas.

\subsection{Effect of urban expansion on the UHI}

To explore the effect of urban expansion on the UHI (Fig. 6), the daily mean, maximum, and minimum surface skin temperatures, for dry days, in July, were compared between the 1980s, 2005, and 2050. The remarkable changes of the daily mean temperature, in the three periods (upper row in Fig. 6), could be captured with the footprint of the urban expansion. The effects of LULC change on the temperature were small for the maximum temperature (middle row in Fig. 6), and the UHI could be hardly identified. The UHI was generally best revealed in the minimum temperature maps in all three scenarios (lower row in Fig. 6). The footprint of the newly developed urban areas was also clearly captured by the maps. Similar spatial patterns can also be observed in the 2-m air
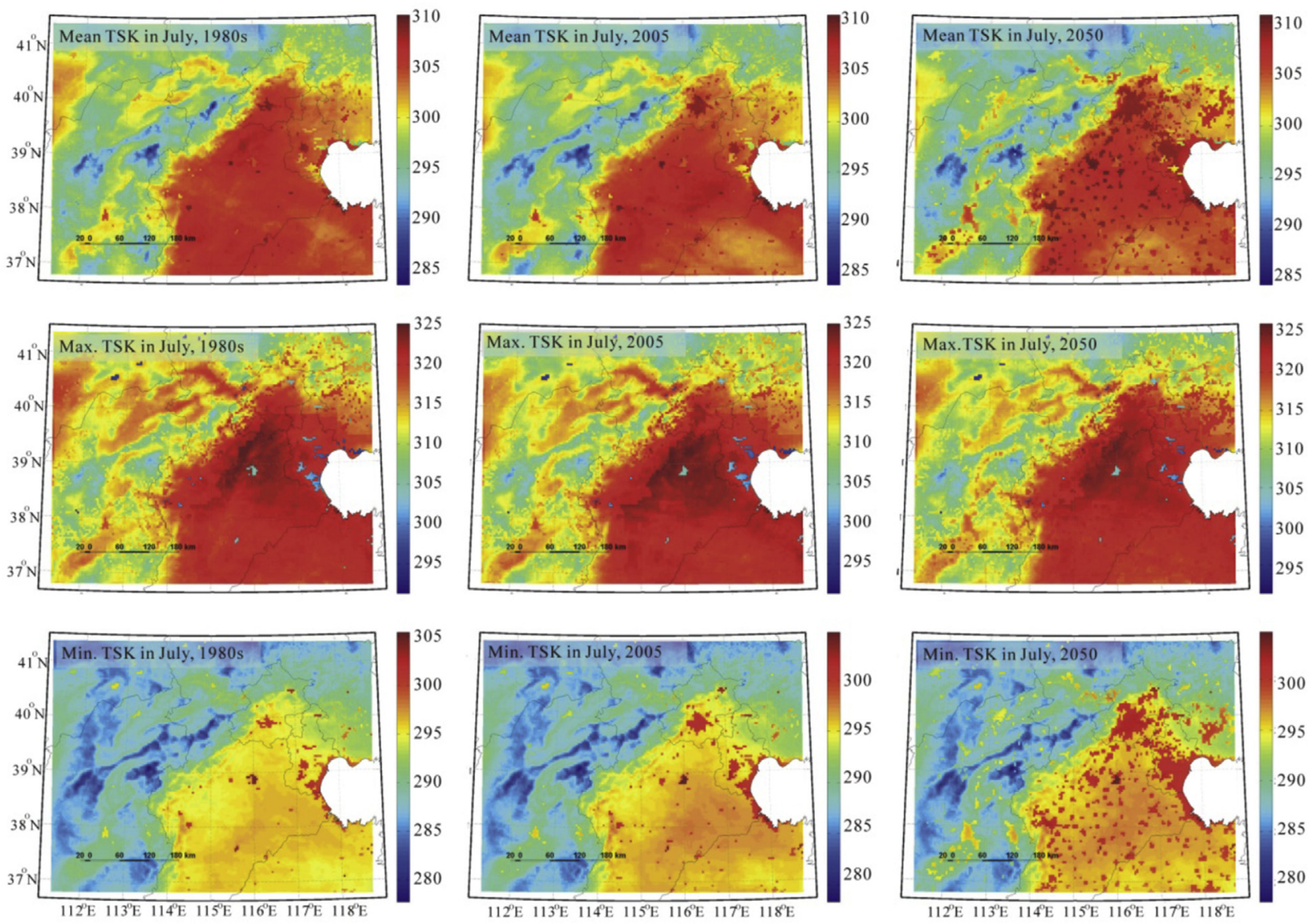

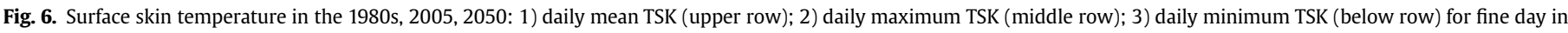
July in the 1980s (left column), 2005 (middle column) and 2050 (right column). 

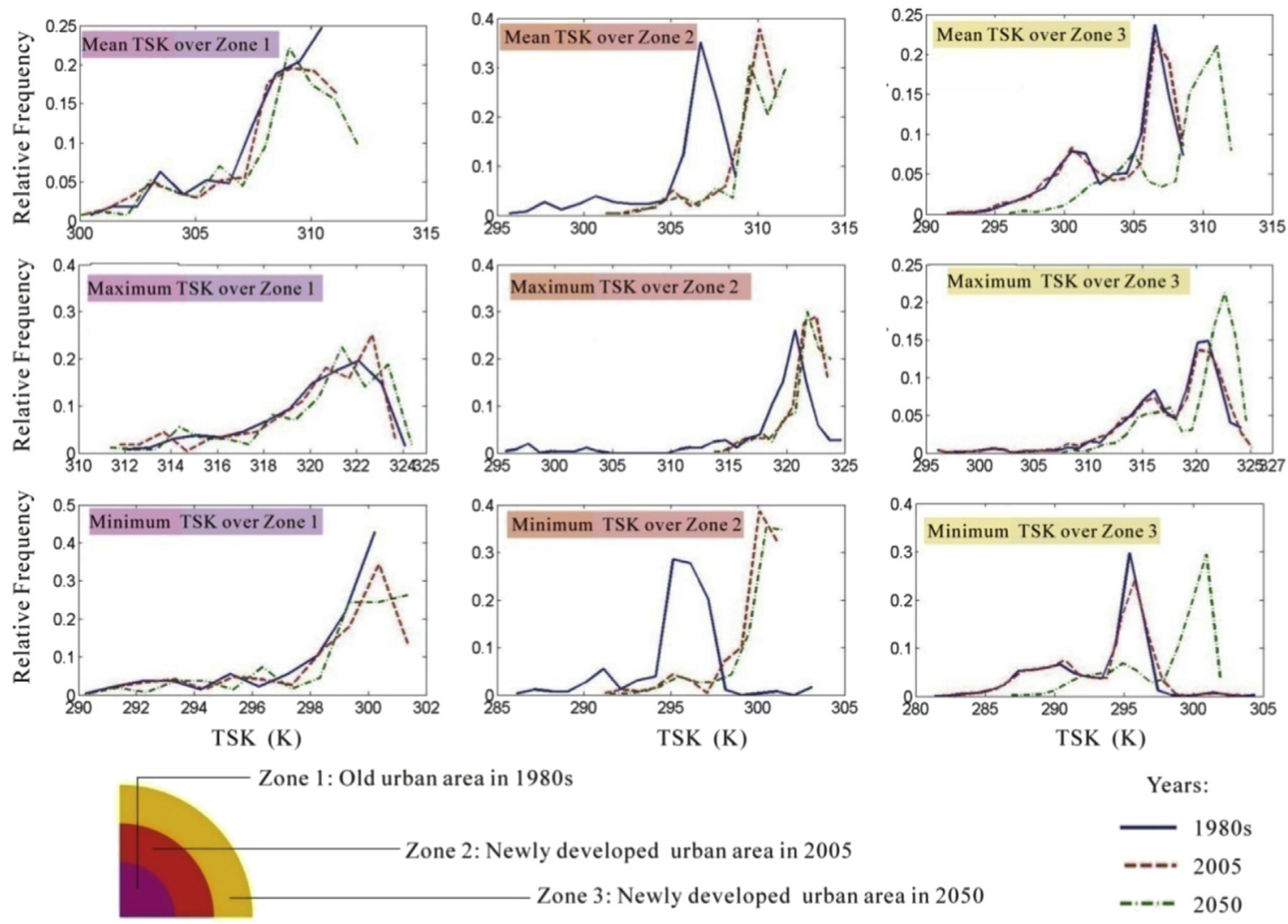

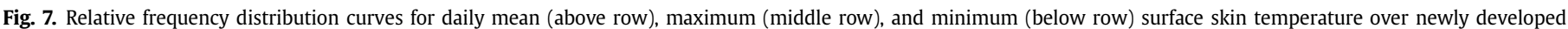
urban areas in the 1980s (left column), 2005 (middle column), and 2050 (right column).

temperature maps (Figures are not shown here).

To confirm the significant effect of urbanization on temperature, especially the minimum temperature, relative frequency distribution curves were plotted highlighting the temperature changes caused by urban expansion (Fig. 7). The changes of mean, maximum, and minimum surface skin temperature, during three scenarios, were barely discernible over the old urban areas in the 1980s (left column in Fig. 7). Over the newly developed urban areas in 2005 (middle column in Fig. 7), the mean, maximum, and minimum surface skin temperature in 2005 and 2050 are obviously larger than those in the 1980s, with an increase of about $5 \mathrm{~K}$ for the mean and minimum surface skin temperature and about $2 \mathrm{~K}$ for the maximum surface skin temperature. The frequency distribution curves for the mean, maximum, and minimum surface skin temperature in 2050, in comparison to the newly developed urban areas in 2050 (right column in Fig. 7), were also clearly distinguishable from the 1980s and 2005, with an increase of about $5 \mathrm{~K}$ for the mean and minimum and about $2 \mathrm{~K}$ for the maximum surface skin temperature. A similar magnitude for the effect of urban growth on the 2-m temperature was also observed.

The largest increase in the minimum temperature by urban expansion also provided evidence through variation in the temperate change at the diurnal scale. Fig. 8 (left panel) presents the diurnal cycles of surface skin temperature in the 1980s, 2005, and 2050 over old urban areas in the 1980s, newly developed urban area in 2005, and newly developed urban area in 2050. There was a distinct increase in surface skin temperatures over the newly developed urban areas, especially during the nighttime. For example, in the case of the newly developed urban area in 2005, the surface skin temperature in 2005 and 2050 increased by about $5 \mathrm{~K}$ during the nighttime and around $2 \mathrm{~K}$ during the daytime compared with that in the 1980s. The 2-m temperature also presented a similar trend. The 2-m air temperature in 2005 and 2050 was about $3 \mathrm{~K}$ higher during the nighttime and $0.5 \mathrm{~K}$ higher during the daytime than that in the 1980s. The newly developed urban areas also increased the temperature over the old urban areas, which can be reflected by the temperature differences between years (right panel in Fig. 8). For example, over the old urban areas in the 1980s, the surface skin temperature in 2005 was about $0.3 \mathrm{~K}$ higher than that in the 1980s during the nighttime and nearly the same during the daytime; the surface skin temperature in 2050 was found to be approximately $0.6 \mathrm{~K}$ higher than in 2005 around at 22:00 and about $0.2 \mathrm{~K}$ higher around at 8:00. In the case of the newly developed urban area in 2005, the surface skin temperature in 2050 was about $0.5 \mathrm{~K}$ higher than that in 2005. The 2-m temperature over the old urban areas increased a little and became a bit higher than the surface skin temperature (figures are not shown here). For example, over the old urban areas in the 1980s, the 2-m temperature in 2005 was about $0.4 \mathrm{~K}$ higher than that in the 1980 s during the nighttime and about $0.1 \mathrm{~K}$ higher during the daytime; the 2-m temperature in 2050 was about $0.8 \mathrm{~K}$ higher than that in 2005 at around 22:00 and about $0.2 \mathrm{~K}$ at around 14:00; the 2-m temperature in 2050 would increase by $1 \mathrm{~K}$ more than the 1980s at around 22:00 and by more than $0.2 \mathrm{~K}$ at around 14:00. It may be caused by the greater mobility of the 2-m temperature fields. It is fair to conclude, in general, that the conversion of land from rural to urban area could significantly increase the temperature, especially the minimum temperature at night. The newly developed urban areas can also facilitate a slight increase slightly in the temperatures in of the older urban areas.

The significant effect of urban expansion on the minimum temperature, together with the largest temperature increase at night, was consistent with the previously observed greater UHI at 

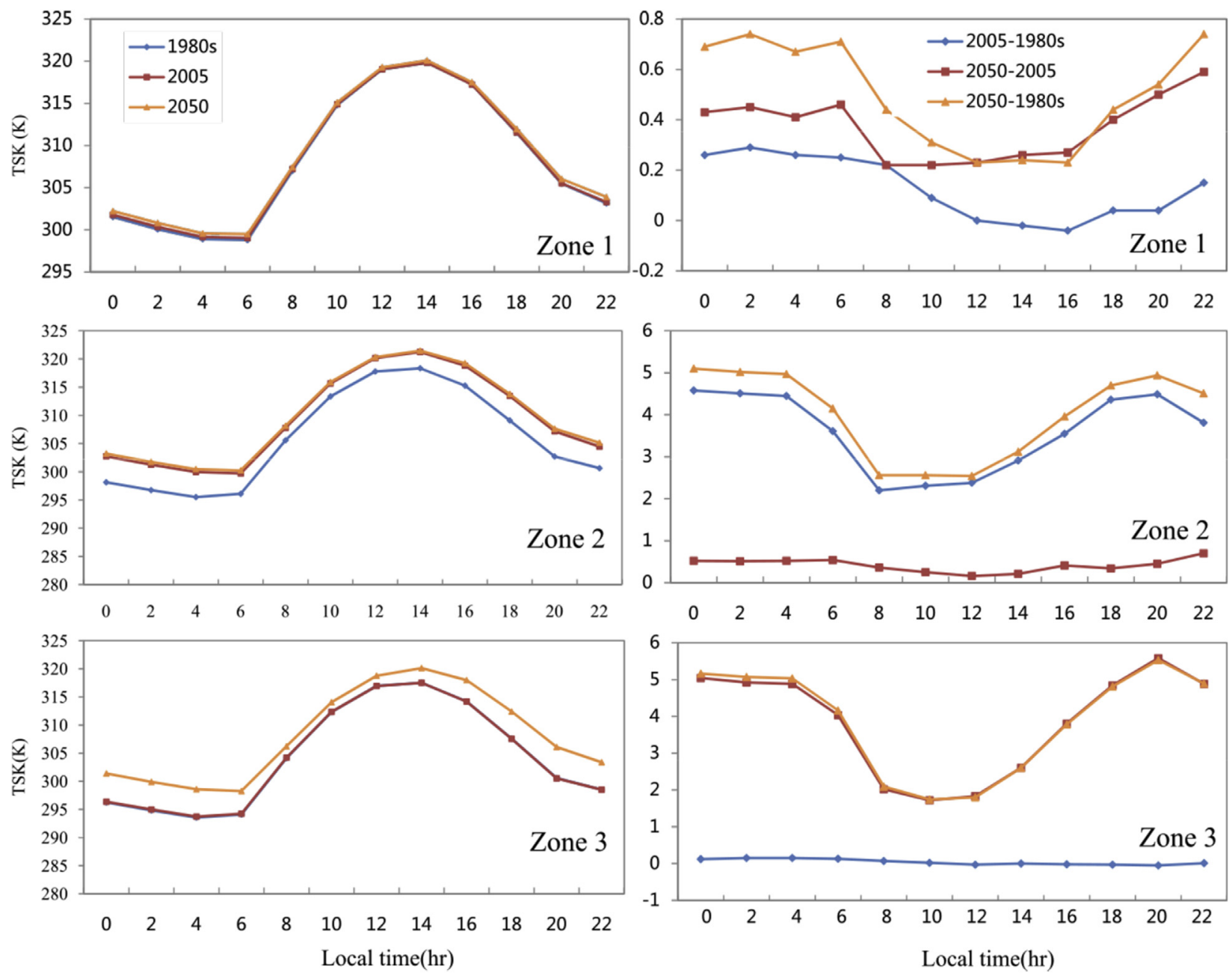

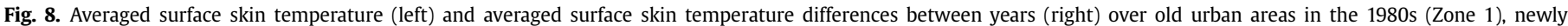
developed urban areas in 2005 (Zone 2), and newly developed urban areas in 2050 (Zone 3).

night. It can be explained by the characteristics of urban constructed surfaces. Impervious urban structures have a higher heat capacity that can store more energy during the daytime and release the heat slowly at night. The low sky view factor also delayed the loss of heat through multiple reflections and the trapping of nearsurface air in urban areas (Argüeso, Evans, Fita, \& Bormann, 2013). However, the opposite is true over rural areas. The differences between urban and rural areas lead to different heat flux characteristics, which finally contribute toward urban expansion leading to increases in the minimum temperature and temperatures getting warm during the night.

We also compared our results with the climatic simulated results from the Intergovernmental Panel on Climate Change/Fifth Assessment Report (IPCC/AR5). According to IPCC/AR5, the temperature changes between June and August ranged from 0 to $8^{\circ} \mathrm{C}$, with increasing amplitude from 2000 to 2100 . During the period 2046 and 2065, the temperature variation would be about $4{ }^{\circ} \mathrm{C}$, which was a little different from our results. This is understandable. However, we considered only urban expansion, while the simulations in the IPCC/AR5 considered both urban expansion and anthropogenic heat discharge. Besides, the future pattern of urbanization in this study was produced from only a statistical predictive model based on five explanatory factors. Although this model has been validated in previous studies (Huang et al., 2009), and can provide a possible urbanized pattern, as a forecast of the real future state there is much uncertainty associated with this model. However, we focused only on the BTH metropolitan area, while the simulated area in the IPCC/AR5 covered Eastern Asia. It is reasonable to believe that the metropolitan areas with intense human activities may have higher temperature changes. It is also suggested to conduct the climatic simulation regionally by accounting for human heat discharge to offer more information about the effect of urbanization on the UHI.

\subsection{Effect of urban expansion on surface heat fluxes}

The thermal properties of the land surface can be altered by urbanization leading to UHI. Diurnal variation in energy fluxes at the ground surface closely correlated to diurnal variation of the UHI. This can, for example (Fig. 9), be documented by the diurnal variations in the heat fluxes over the newly developed urban area in 2005. During the 1980s, this zone fell under rural areas and eventually became urban area in 2005 and 2050.

Urbanization can largely increase the sensible heat fluxes by decreasing the latent heat flux (Fig. 9a-b). The urban surface had much higher sensible heat flux and much lower latent heat flux than rural areas due, in part, to lower evaporation over the urban surface. Although both the urban and rural areas had roughly the same short-wave fluxes (Fig. 9c), the urban area gained more radiation and stored more heat than rural areas (Fig. 9e). Also, a 

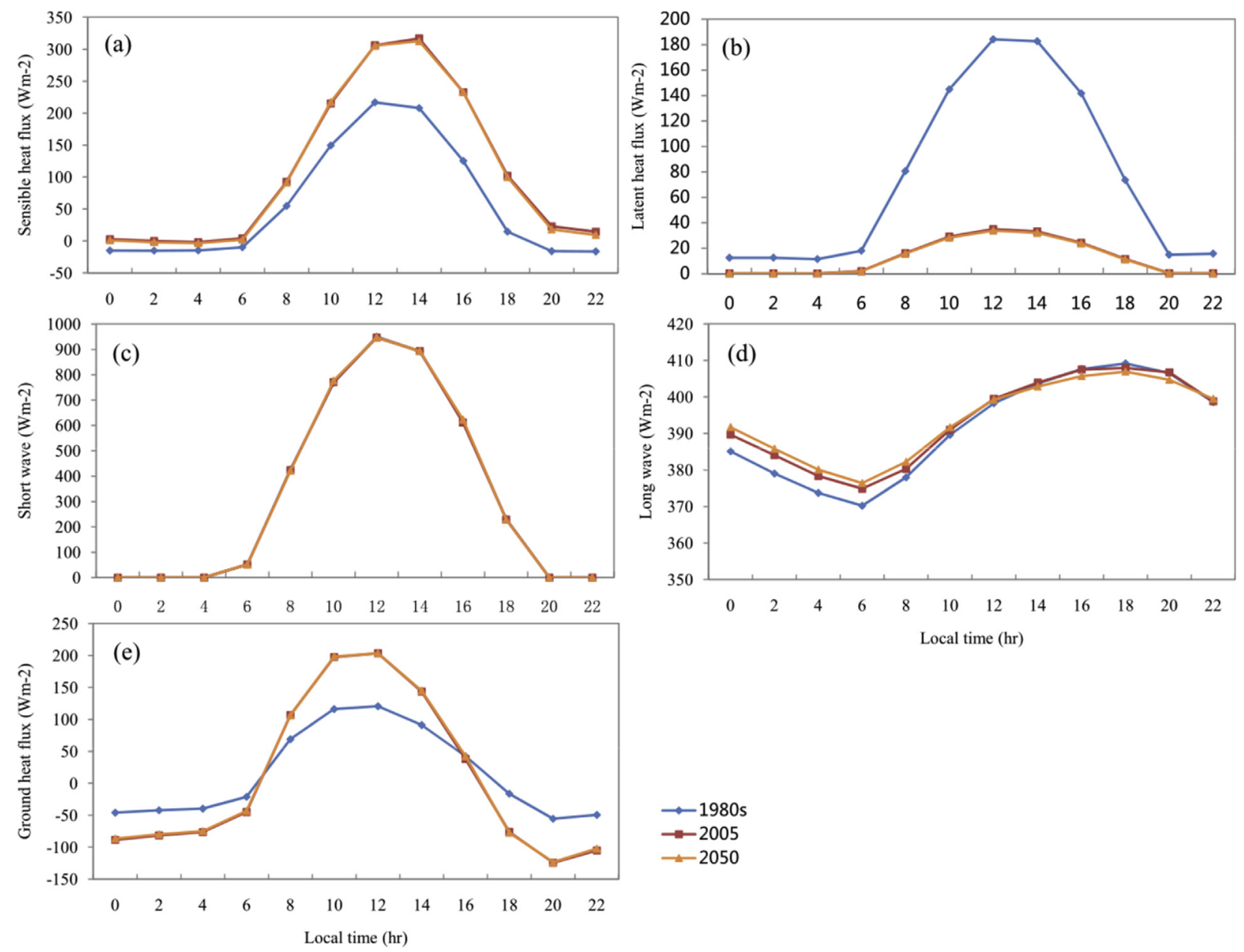

Fig. 9. Heat fluxes in July 1980s, 2005, and 2050 over newly developed urban areas in 2005.

higher surface temperature in urban area was expected because of its large heat storage during the daytime. The active heat fluxes between the underlying surface and the atmosphere also led to the much higher air temperature over urban regions. The long-wave flux witnessed in urban areas was much larger in comparison to rural areas (Fig. 9d) during the night. Although the urban surface cools during the night, the large quantity of heat stored on the surface together with heat conductivity makes the surface temperature in the urban area much higher than the surface in rural areas at night. During the nighttime, the larger long-wave fluxes can heat the atmosphere in urban areas. During the nighttime, however, rural surfaces cooled rapidly. Rural regions witness heat fluxes that heat up the land underlying the surface, thereby heating the atmosphere. At night, the air temperature over urban regions was much higher than that over the rural regions. This explains why both the surface UHII and air UHII were much larger during the nighttime.

\section{Summary}

This study was conducted using the BTH metropolitan area as the area of the study to ascertain the effect of urban expansion on the UHI using the coupled WRF/UCM modeling system. Fine spatial resolution LULC data in the 1980s and 2005 and urban expansion in 2050, predicted using a statistical land conversion model, were used in this study. The significant effect of urbanization on temperatures, especially the minimum temperature, was quantified over both the newly developed and the old urban areas, by evaluating the three scenarios in the sensitivity experiments.

Both the surface UHI and air UHI shared consistent seasonal and diurnal variations. The UHI can be observed distinctly in July, while is not so obvious in January. The UHII was larger during the nighttime and reached the largest value around 04:00 in July. It was much weaker during the daytime and reached the lowest value around 12:00. The diurnal variation in AUHII was consistent with the SUHII, but about $2 \mathrm{~K}$ lower than the SUHII during the nighttime and about $1 \mathrm{~K}$ lower during the daytime.

Urban expansion significantly affected the minimum temperature. The UHI can be observed in all three scenarios, and the footprint of the newly developed urban areas can be captured, especially in the map showing the minimum temperature. While the maximum temperature increased by about $2 \mathrm{~K}$, both the mean and the minimum temperature would increase by about $5 \mathrm{~K}$ over the newly developed urban area. The temperature over the old urban area would also increase due to urban growth (by $<1 \mathrm{~K}$ ). The results point to a more uncomfortable urban environment in the future, with higher heat storage due to urbanization, especially during the nighttime, when temperature changes are greater due to urban expansion. 


\section{Acknowledgments}

This study was funded by the National Natural Science Foundation of China (Nos.: 41371417, 41501473, and 41421001) and the Incubation Programme of Great Wall Scholars of Beijing Municipal University \& College (No.: IDHT20130322). PMA is grateful to the University of Utrecht for supporting him with The Belle van Zuylen Chair.

\section{References}

Argüeso, D., Evans, J., Fita, L., \& Bormann, K. (2013). Temperature response to future urbanization and climate change. Climate Dynamics, 1-17.

Bounoua, L., Safia, A., Masek, J., Peters-Lidard, C., \& Imhoff, M. L. (2009). Impact of urban growth on surface climate: a case study in Oran, Algeria. Journal of Applied Meteorology and Climatology, 48, 217-231.

Cheng, C. K. M., \& Chan, J. C. L. (2012). Impacts of land use changes and synoptic forcing on the seasonal climate over the Pearl River Delta of China. Atmospheric Environment, 60, 25-36.

Chen, F., Kusaka, H., Bornstein, R., Ching, J., Grimmond, C. S. B., Grossman-Clarke, S., et al. (2011). The integrated WRF/urban modelling system: development, evaluation, and applications to urban environmental problems. International Journal of Climatology, 31, 273-288.

Chen, F., Manning, K. W., Yates, D. N., LeMone, M. A., Trier, S. B., Cuenca, R., et al. (2004). Development of high resolution land data assimilation system and its application to WRF. In 16th Conf. on Numerical Weather Prediction, Seattle, WA, Amer. Meteor. Soc. Preprints.

Chen, X. L., Zhao, H. M., Li, P. X., \& Yin, Z. Y. (2006). Remote sensing image-based analysis of the relationship between urban heat island and land use/cover changes. Remote Sensing of Environment, 104, 133-146.

Connors, J., Galletti, C., \& Chow, W. L. (2013). Landscape configuration and urban heat island effects: assessing the relationship between landscape characteristics and land surface temperature in Phoenix, Arizona. Landscape Ecology, 28, $271-283$.

Gallo, K., Hale, R., Tarpley, D., \& Yu, Y. Y. (2011). Evaluation of the relationship between air and land surface temperature under clear- and cloudy-sky conditions. Journal of Applied Meteorology and Climatology, 50, 767-775.

Gallo, K. P., \& Tarpley, J. D. (1996). The comparison of vegetation index and surface temperature composites for urban heat-island analysis. International Journal of Remote Sensing, 17, 3071-3076.

Guo, Z., Wang, S. D., Cheng, M. M., \& Shu, Y. (2012). Assess the effect of different degrees of urbanization on land surface temperature using remote sensing images. Procedia Environmental Sciences, 13, 935-942.

He, J. F., Liu, J. Y., Zhuang, D. F., Zhang, W., \& Liu, M. L. (2007). Assessing the effect of land use/land cover change on the change of urban heat island intensity. Theoretical and Applied Climatology, 90, 217-226.

Huang, B., Zhang, L., \& Wu, B. (2009). Spatiotemporal analysis of rural-urban land conversion. International Journal of Geographical Information Science, 23, 379-398.

Kusaka, H., \& Kimura, F. (2004). Thermal effects of urban canyon structure on the nocturnal heat island: numerical experiment using a meso-scale model coupled with an urban canopy model. Journal of Applied Meteorology, 43, 1899-1910.

Kusaka, H., Kondo, H., Kikegawa, Y., \& Kimura, F. (2001). A simple single-layer urban canopy model for atmospheric models: comparison with multi-layer and slab models. Boundary-Layer Meteorology, 101, 329-358.

Lin, C. Y., Chen, W. C., Chang, P. L., \& Sheng, Y. F. (2010). Impact of the urban heat island effect on precipitation over a complex geographic environment in northern Taiwan. Journal of Applied Meteorology and Climatology, 50, 339-353.

Lin, C. Y., Chen, F., Huang, J. C., Chen, W. C., Liou, Y. A., Chen, W. N., et al. (2008). Urban heat island effect and its impact on boundary layer development and land-sea circulation over northern Taiwan. Atmospheric Environment, 42, 5635-5649.

Liu, S., Li, Q., \& Zhu, Y. J. (2014). Study on seasonal variation of urban heat island with HJ-1B satellite imagery: a case study of Beijing. Scientia Geographical Sinica, 34(1), 84-88.

Liu, M. L., \& Tian, H. Q. (2010). China's land cover and land use change from 1700 to 2005: estimations from high-resolution satellite data and historical archives. Global Biogeochemical Cycles, 24.

Miao, S., Chen, F., LeMone, M. A., Tewari, M., Li, Q., \& Wang, Y. (2009). An observational and modeling study of characteristics of urban heat island and boundary layer structures in Beijing. Journal of Applied Meteorology and Climatology, 48, 484-501.

Qiao, Z., Tian, G. G., \& Xiao, L. (2013). Diurnal and seasonal impacts of urbanization on the urban thermal environment: a case study of Beijing using MODIS data. Journal of Photogrammetry and Remote Sensing, 85, 93-101.

Skamarock, W. C., Klemp, J. B., Dudhia, J., Gill, D. O., Barker, D. M., Wang, W., et al. (2005). A description of the advanced research WRF version 2. In DTIC Document.

Voogt, J. A., \& Oke, T. R. (2003). Thermal remote sensing of urban climates. Remote Sensing of Environment, 86, 370-384.

Wang, J., Feng, J., Yan, Z., Hu, Y., \& Jia, G. (2012). Nested high-resolution modeling of the impact of urbanization on regional climate in three vast urban agglomerations in China. Journal of Geophysical Research: Atmospheres, 117, D21103.

Wang, J. K., Wang, K. C., \& Wang, P. C. (2007). Urban heat (or cool) island over Beijing from MODIS land surface temperature. Journal of Remote Sensing, 11(3) 330-339.

Wang, X., Wu, Z., \& Liang, G. (2009). WRF/CHEM modeling of impacts of weather conditions modified by urban expansion on secondary organic aerosol formation over Pearl River Delta. Particuology, 7, 384-391.

Wang, M., Yan, X., Liu, J., \& Zhang, X. (2013). The contribution of urbanization to recent extreme heat events and a potential mitigation strategy in the Beijing-Tianjin-Hebei metropolitan area. Theoretical and Applied Climatology $1-10$.

Wang, M., Zhang, X., \& Yan, X. (2013). Modeling the climatic effects of urbanization in the Beijing-Tianjin-Hebei metropolitan area. Theoretical and Applied Climatology, 113, 377-385.

Weng, Q. H. (2009). Thermal infrared remote sensing for urban climate and environmental studies: methods, applications, and trends. Journal of Photogrammetry and Remote Sensing, 64(4), 335-344.

Weng, Q. Lu, D., \& Liang, B. (2006). Urban surface biophysical descriptors and land surface temperature variations. Photogrammetric Engineering \& Remote Sensing, 72, 1275-1286.

Weng, Q. H., Lu, D. S., \& Schubring, J. (2004). Estimation of land surface temperature-vegetation abundance relationship for urban heat island studies. Remote Sensing of Environment, 89, 467-483.

Wu, R., Hu, Z. Z., \& Kirtman, B. P. (2003). Evolution of ENSO-related rainfal anomalies in East Asia and the processes. Journal of Climate, 16, 3741-3757.

Yang, B., Zhang, Y., \& Qian, Y. (2012). Simulation of urban climate with highresolution WRF model: a case study in Nanjing, China. Asia-Pacific Journal of Atmospheric Sciences, 48, 227-241.

Yang, S. B., Zhao, X. Y. Shen, S. H., Hai, Y L. \& Fang Y. X. (2010). Characteristics of urban heat island seasonal pattern in Beijing based on Landsat TM/ETM+ image. Transactions of Atmospheric Sciences, 33(4), 427-435.

Zhang, C. L., Chen, F., Miao, S. G., Li, O. C., Xia, X. A., \& Xuan, C. Y. (2009). Impacts of urban expansion and future green planting on summer precipitation in the Beijing metropolitan area. Journal of Geophysical Research: Atmospheres, 114, D02116.

Zhang, N., Gao, Z., Wang, X., \& Chen, Y. (2010). Modeling the impact of urbanization on the local and regional climate in Yangtze River Delta, China. Theoretical and Applied Climatology, 102, 331-342.

Zhang, G. H., Hou, Y. Y., Li, G. C., Yan, H., \& Yang, L. M. (2005). Studies on the diurna and seasonal variations in the urban heat island and its factors in Beijing city and its surrounding areas based on the remote sensing images. Science in China (Series D), 35, 187-194.

Zhang, H., Oi, Z., Ye, X., Cai, Y., Ma, Y., \& Chen, M. (2013). Analysis of land use/land cover change, population shift, and their effects on spatiotemporal patterns of urban heat islands in metropolitan Shanghai, China. Applied Geography, 44 $121-133$ 